\title{
Chronic and Recurrent Depression in Primary Care: Socio-Demographic Features, Morbidity, and Costs
}

\author{
Elaine M. McMahon, ${ }^{1}$ Marta Buszewicz, ${ }^{1}$ Mark Griffin, ${ }^{1}$ Jennifer Beecham, ${ }^{2,3}$ \\ Eva-Maria Bonin, ${ }^{2}$ Felicitas Rost, ${ }^{1}$ Kate Walters, ${ }^{1}$ and Michael King ${ }^{4}$ \\ ${ }^{1}$ Research Department of Primary Care and Population Health, University College London, Upper Third Floor, \\ Royal Free Hospital, Rowland Hill Street, London NW3 2PF, UK \\ ${ }^{2}$ Personal Social Services Research Unit, London School of Economics and Political Science, Houghton Street, \\ London WC2A 2AE, UK \\ ${ }^{3}$ Personal Social Services Research Unit, University of Kent, Cornwallis Building, Canterbury, Kent CT2 7NF, UK \\ ${ }^{4}$ Research Department of Mental Health Sciences, University College London, Royal Free Campus, \\ Rowland Hill Street, London NW3 2PF, UK
}

Correspondence should be addressed to Elaine M. McMahon, emcmahon77@gmail.com

Received 9 January 2012; Revised 28 March 2012; Accepted 1 April 2012

Academic Editor: Jan De Lepeleire

Copyright ( $) 2012$ Elaine M. McMahon et al. This is an open access article distributed under the Creative Commons Attribution License, which permits unrestricted use, distribution, and reproduction in any medium, provided the original work is properly cited.

\begin{abstract}
Background. Major depression is often chronic or recurrent and is usually treated within primary care. Little is known about the associated morbidity and costs. Objectives. To determine socio-demographic characteristics of people with chronic or recurrent depression in primary care and associated morbidity, service use, and costs. Method. 558 participants were recruited from 42 GP practices in the UK. All participants had a history of chronic major depression, recurrent major depression, or dysthymia. Participants completed questionnaires including the BDI-II, Work and Social Adjustment Scale, Euroquol, and Client Service Receipt Inventory documenting use of primary care, mental health, and other services. Results. The sample was characterised by high levels of depression, functional impairment, and high service use and costs. The majority (74\%) had been treated with an antidepressant, while few had seen a counsellor $(15 \%)$ or a psychologist $(3 \%)$ in the preceding three months. The group with chronic major depression was most depressed and impaired with highest service use, whilst those with dysthymia were least depressed, impaired, and costly to support but still had high morbidity and associated costs. Conclusion. This is a patient group with very significant morbidity and high costs. Effective interventions to reduce both are required.
\end{abstract}

\section{Introduction}

In the UK, clinically significant or major depression affects between $5 \%$ and $10 \%$ of people at any time, with most being treated within general practice [1]. The annual cost of depression has been estimated to be over $£ 9$ billion in England [2], with more than 100 million working days lost and over 2,500 deaths due to depression in 2000 [2].

Major depression is often a chronic or recurrent disorder, with an estimated $80 \%$ of people experiencing at least one recurrence, although one primary care study has reported recurrence rates as low as $40 \%$ after a first episode [3]. Approximately $12 \%$ follow a chronic course [4]. Results from other studies indicate that only $50 \%$ of those with major depression will have recovered at one year [5]. The risk of recurrence increases with each successive episode [6].

Primary care populations with chronic or recurrent depression, although clinically important, are rarely investigated as a distinct patient group [7]. Past work has shown that chronicity is associated with high mortality, greater psychological and social morbidity, high use of primary care services [8], and high social and financial costs [3]. However, we have little detailed information on the specific morbidity, functional impairment, health service use or costs of chronic or recurrent depression in primary care settings.

In this study, our aims were to examine sociodemographic characteristics, morbidity, service use, and associated costs for three main clinical groups of people 
Recurrent major depression

Recurrent major depression was defined by participants having two or more episodes of major depression within a three-year period. An episode of major depression must last at least two weeks with a period of recovery lasting at least two months in between episodes and must interfere with the person's normal functioning.

Dysthymia

Dysthymia lasts at least two years, with symptoms which are less severe than those of major depression, but which nonetheless impair the individual's functioning.

Chronic major depression

An episode of major depression which lasts for a full two year period without a break of two months or more in which the person could function normally.

Box 1: DSM-IV diagnoses included in the ProCEED study.

with depression. Our sample comprised people looked after in primary care who were diagnosed with chronic major depression, recurrent major depression, and dysthymia. We addressed three main questions as follows.

(1) What were the socio-demographic characteristics of people in these three groups, and were there differences between the groups?

(2) Were there differences in the associated morbidity?

(3) What services were used by these three groups, and what were the associated costs?

\section{Methods}

2.1. Recruitment. A total of 558 participants were recruited between November 2007 and July 2008 from 42 GP practices in England, Scotland, and Northern Ireland. The aim was to recruit a representative sample of practices from throughout the UK, including urban and rural areas and areas with diverse ethnic populations. Participants were identified to be part of multi-centre study to test whether regular proactive contact with a practice nurse would benefit people with chronic or recurrent depression [9]. Patients were eligible if they were over the age of 18 , had a recent history of chronic or recurrent major depression or dysthymia based on the Composite International Diagnostic Interview (CIDI), and their symptoms indicated at least mild depression (scoring 14 or higher on the Beck Depression Inventory; BDI-II). Patients with impaired cognitive function, current psychotic symptoms, or incapacitating drug or alcohol dependence were excluded. All patients who met eligibility criteria and who consented to participate were included in the study. Recruitment procedures, inclusion/exclusion criteria, and outcome measures used have been fully described elsewhere [9]. The findings reported here are based on pooled data collected at baseline from both intervention and control participants before the intervention began.

2.2. Measures. Prior to enrolment, participants were interviewed by the practice/research nurse to check eligibility. The nurses had been trained to conduct the recruitment interview. Research questionnaires were completed by eligible participants immediately after the interview and prior to randomisation.

The CIDI was administered by the nurse to check eligibility. Eligible participants met criteria for one of three DSM-IV diagnoses as described in Box 1 [10].

The self-report questionnaires completed included assessment of severity of depressive symptoms using the BDI-II, a widely used 21-item questionnaire [11]. Functional impairment was measured using the Work and Social Adjustment Scale (WSAS), a 5-item measure of impairment attributable to an identified problem (e.g., depression) [12]. Service use was assessed using the Client Service Receipt Inventory (CSRI), a self-complete record of demographic data, medication, and health and community service use for the three months prior to recruitment [13].

Cost Calculations. The costs of service use for each person were calculated by identifying an appropriate unit cost for each contact and multiplying it by the number of contacts each person recorded on the CSRI. For most hospital, mental health and primary care services as well as social service interventions, unit costs were drawn from publicly available sources $[14,15]$. The remainder was taken from previous studies or estimated using an equivalent method [16]. Where the number of service contacts was missing, the mean for the whole group or a minimum of one contact was used. All costs are presented in 2008 prices.

2.3. Data Analysis. Descriptive statistics were produced for socio-demographic characteristics, BDI II and WSAS, by each diagnostic group. Findings are presented as percentages for categorical variables and means, and standard deviations are used for continuous variables as the data were found to be approximately normally distributed.

The proportion of people using selected services and the contact rates are reported by diagnostic group. Costs are compared between diagnostic groups using $t$-tests with 1,000 bootstrap replications [17] using STATA version 10.0 and SPSS version 17.0 software. 
TABle 1: Socio-demographic and diagnostic characteristics.

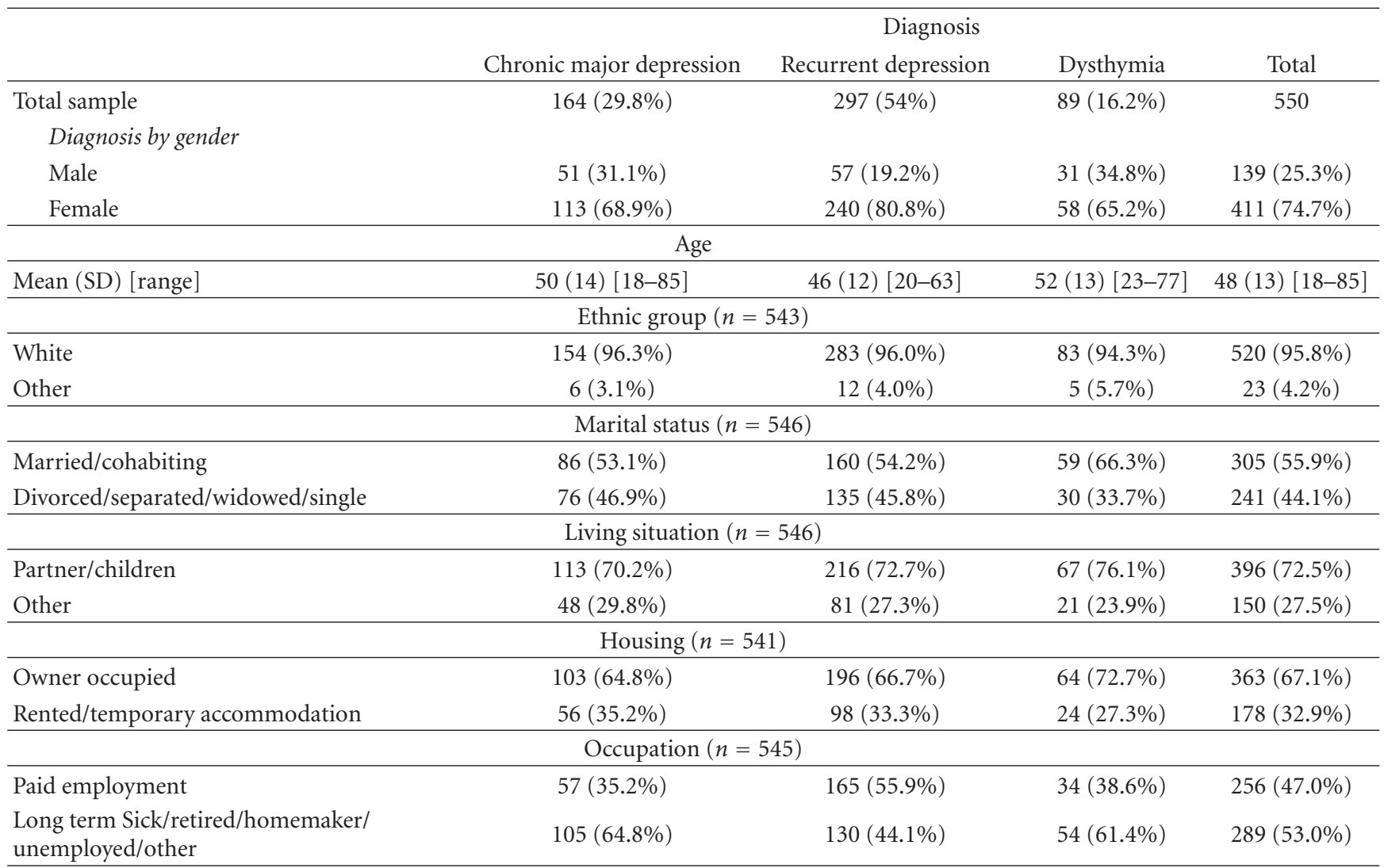

\section{Results}

\subsection{Characteristics of the Sample}

3.1.1. Socio-Demographic Characteristics. Table 1 reports the demographic and diagnostic characteristics of the study sample; $54 \%$ of participants met criteria for recurrent major depression, $30 \%$ for chronic major depression, and $16 \%$ for dysthymia. The average age of the sample was 48 years, and $75 \%$ were female. Two thirds were owner occupiers of their homes. Just under half were in paid employment. A greater proportion of those with dysthymia were married or cohabiting $(66 \%)$ compared to those with chronic major depression (53\%) or recurrent depression (54\%). Over half of those with recurrent depression were in paid employment (56\%), compared to just $35 \%$ of those with chronic major depression and $39 \%$ of those with dysthymia.

3.1.2. Depression and Functional Impairment. Tables 2 and 3 report participants' scores on measures of depression and functional impairment by diagnostic group. Higher scores on the BDI-II and WSAS scales indicate higher levels of depression and functional impairment. $62 \%$ of the entire sample were categorised as severely depressed [11] and $61 \%$ categorised as moderately or severely functionally impaired [12]. Those with chronic major depression had the highest mean BDI II score, and $76 \%$ of this group were severely depressed, compared with $57 \%$ of those with recurrent depression and 54\% with dysthymia. Participants with chronic major depression also had the highest mean WSAS impairment score with $69 \%$ of this group at least moderately impaired.

3.1.3. Service Use and Costs. Costs were available for 549 participants, although we excluded one person who remained in hospital for the full period as no community or primary care services were used. Table 4 identifies service use patterns between the groups, showing in detail the use of GP, practice nurse, and mental health services and conflating others into five main categories. In the previous 3 months, $63 \%$ of the chronic major depression group had consulted a GP for depression, a higher proportion than either the recurrent depression or dysthymia groups. However, the dysthymia group had the highest proportion who reported any primary care consultations for all reasons in the past three months $(89 \%)$. A minority of the total sample had seen a counsellor $(15 \%)$ or a psychologist $(3 \%)$.

Across the whole sample, a wide range of services was used although, with the notable exception of primary care, most services were only used by one or two people. Very few people across the whole sample had seen a secondary care mental health professional, either a psychiatrist (5\%) or psychologist (3\%), while around a sixth (15\%) had had contact with a practice counsellor. Despite the differences in severity 
TABLE 2: Severity of depression by diagnostic group.

\begin{tabular}{|c|c|c|c|c|}
\hline & \multicolumn{4}{|c|}{ Diagnosis } \\
\hline & $\begin{array}{c}\text { Chronic major depression } \\
\qquad(n=164)\end{array}$ & $\begin{array}{l}\text { Recurrent depression } \\
\qquad(n=297)\end{array}$ & $\begin{array}{l}\text { Dysthymia } \\
(n=89)\end{array}$ & $\begin{array}{c}\text { Total } \\
(n=550)\end{array}$ \\
\hline \multicolumn{5}{|c|}{ BDI-II total score } \\
\hline Mean (SD) & $36.0(10.7)$ & $31.4(9.9)$ & $29.76(8.6)$ & $32.52(10.2)$ \\
\hline Range & $14-60$ & $14-57$ & $14-49$ & $14-60$ \\
\hline \multicolumn{5}{|c|}{ BDI-II depression severity } \\
\hline Mild depression & $11(6.7 \%)$ & $39(13.1 \%)$ & $11(12.4 \%)$ & $61(11.1 \%)$ \\
\hline Moderate depression & $29(17.7 \%)$ & $88(29.6 \%)$ & $30(33.7 \%)$ & $147(26.7 \%)$ \\
\hline Severe depression & $124(75.6 \%)$ & $170(57.2 \%)$ & $48(53.9 \%)$ & $342(62.2 \%)$ \\
\hline
\end{tabular}

TABLE 3: Severity of functional impairment by diagnostic group.

\begin{tabular}{|c|c|c|c|c|}
\hline & \multicolumn{4}{|c|}{ Diagnosis } \\
\hline & $\begin{array}{c}\text { Chronic major depression } \\
\qquad(n=163)\end{array}$ & $\begin{array}{l}\text { Recurrent depression } \\
\quad(n=296)\end{array}$ & $\begin{array}{l}\text { Dysthymia } \\
(n=88)\end{array}$ & $\begin{array}{c}\text { Total } \\
(n=547)\end{array}$ \\
\hline \multicolumn{5}{|c|}{ WSAS total score } \\
\hline Mean (SD) & $24.97(9.7)$ & $21.41(9.4)$ & $20.38(8.4)$ & $22.3(9.5)$ \\
\hline Range & $0-40$ & $0-40$ & $3-38$ & $0-40$ \\
\hline \multicolumn{5}{|c|}{ WSAS impairment severity } \\
\hline Subclinical impairment & $11(6.7 \%)$ & $40(13.5 \%)$ & $10(11.4 \%)$ & $61(11.2 \%)$ \\
\hline Significant impairment & $39(23.9 \%)$ & $84(28.4 \%)$ & $29(33.0 \%)$ & $152(27.8 \%)$ \\
\hline Moderately severe or worse impairment & $113(69.3 \%)$ & $172(58.1 \%)$ & $49(55.7 \%)$ & $334(61.1 \%)$ \\
\hline
\end{tabular}

TABLE 4: Service use over 3 months, by diagnostic group.

\begin{tabular}{|c|c|c|c|c|c|c|c|c|}
\hline \multirow{2}{*}{ Service $^{\mathrm{a}}$} & \multicolumn{2}{|c|}{ Chronic major depression $(n=163)$} & \multicolumn{2}{|c|}{ Recurrent depression $(n=296)$} & \multicolumn{2}{|c|}{ Dysthymia $(n=89)$} & \multicolumn{2}{|c|}{ Total $(n=548)$} \\
\hline & $\%$ using service & $\begin{array}{l}\text { Mean number } \\
\text { contacts }\end{array}$ & $\begin{array}{l}\text { \% using } \\
\text { service }\end{array}$ & $\begin{array}{c}\text { Mean } \\
\text { number } \\
\text { contacts }\end{array}$ & $\begin{array}{l}\text { \% using } \\
\text { service }\end{array}$ & $\begin{array}{c}\text { Mean } \\
\text { number } \\
\text { contacts }\end{array}$ & $\begin{array}{l}\text { \% using } \\
\text { service }\end{array}$ & $\begin{array}{c}\text { Mean } \\
\text { number } \\
\text { contacts }\end{array}$ \\
\hline GP (depression) & $63 \%$ & 1.16 & $57 \%$ & 1.16 & $58 \%$ & 1.16 & $59 \%$ & 1.16 \\
\hline GP (other reason) & $61 \%$ & 1.38 & $57 \%$ & 1.16 & $67 \%$ & 1.29 & $60 \%$ & 1.25 \\
\hline $\begin{array}{l}\text { Practice nurse } \\
\text { (depression) }\end{array}$ & $9 \%$ & 0.12 & $5 \%$ & 0.06 & $9 \%$ & 0.12 & $7 \%$ & 0.09 \\
\hline Practice nurse (other) & $33 \%$ & 0.51 & $31 \%$ & 0.49 & $28 \%$ & 0.40 & $31 \%$ & 0.49 \\
\hline Any primary care & $85 \%$ & 一 & $88 \%$ & - & $89 \%$ & - & $87 \%$ & - \\
\hline Psychiatrist & $4 \%$ & 0.13 & $5 \%$ & 0.08 & $4 \%$ & 0.07 & $5 \%$ & 0.09 \\
\hline Psychologist & $7 \%$ & $0.31^{3}$ & $1 \%$ & $0.03^{3}$ & $3 \%$ & 0.06 & $3 \%$ & 0.11 \\
\hline Counsellor & $16 \%$ & $0.93^{2}$ & $16 \%$ & $0.92^{1}$ & $9 \%$ & $0.33^{1}$ & $15 \%$ & 0.82 \\
\hline $\begin{array}{l}\text { Any mental health } \\
\text { contacts }\end{array}$ & $28 \%$ & - & $28 \%$ & - & $16 \%$ & - & $26 \%$ & - \\
\hline Any hospital services & $40 \%$ & - & $35 \%$ & - & $37 \%$ & - & $37 \%$ & 一 \\
\hline Any alternative therapy & $7 \%$ & $0.21^{2}$ & $11 \%$ & $0.78^{1}$ & $1 \%$ & $0.01^{1,2}$ & $9 \%$ & 0.48 \\
\hline $\begin{array}{l}\text { Any other health and } \\
\text { community services }\end{array}$ & $26 \%$ & - & $25 \%$ & - & $27 \%$ & - & $26 \%$ & - \\
\hline Anti-depressants & $80 \%$ & - & $72 \%$ & - & $70 \%$ & - & $74 \%$ & - \\
\hline Other medications & $77 \%$ & - & $63 \%$ & - & $79 \%$ & - & $70 \%$ & - \\
\hline \multicolumn{9}{|c|}{$\begin{array}{l}\text { any primary care includes all GP and practice nurse contacts, other primary care services. Any mental health services include psychiatrist, psychologist, } \\
\text { counsellor, psychotherapy, psychiatric community nurse. Any hospital services include inpatient and outpatient services for depression or other reason, A\&E } \\
\text { or minor injuries unit. Any alternative therapy includes, for example, hydrotherapy, spiritual healing. Any other health and community services include } \\
\text { community health services, social work and other social care, self-help and support services, support provided by the voluntary sector. } \\
{ }^{1} \text { Significant difference between dysthymia and recurrent depression groups. } \\
{ }^{2} \text { Significant difference between dysthymia and chronic major depression groups. } \\
{ }^{3} \text { Significant difference between recurrent depression and chronic major depression groups. }\end{array}$} \\
\hline
\end{tabular}


TABLE 5: Average costs over three months, by service category and diagnostic group.

\begin{tabular}{|c|c|c|c|c|}
\hline \multirow[t]{2}{*}{ Service category ${ }^{\mathrm{a}}$} & $\begin{array}{c}\text { Chronic major } \\
\text { depression }(n=163)\end{array}$ & $\begin{array}{l}\text { Recurrent depression } \\
\qquad(n=296)\end{array}$ & Dysthymia $(n=89)$ & Total $(n=548)$ \\
\hline & Mean costs (SD) & Mean costs (SD) & Mean costs (SD) & Mean costs (SD) \\
\hline Primary care & $\mathfrak{£} 96(80)$ & $\mathfrak{E} 88(77)$ & $\mathfrak{E} 92(67)$ & $91(77)$ \\
\hline Mental health & $£ 147^{2}(401)$ & $£ 107^{1}(317)$ & $£ 40^{1,2}(136)$ & $105(325)$ \\
\hline Hospital & $\mathfrak{E} 176(463)$ & $\mathfrak{E} 154(520)$ & $\mathfrak{E} 107(230)$ & $153(467)$ \\
\hline Alternative therapy & $\mathfrak{E} 9^{2,3}(48)$ & $\mathfrak{E} 33^{1,3}(235)$ & $\mathfrak{E} 0^{1,2}(4)$ & $21(175)$ \\
\hline $\begin{array}{l}\text { Other health and community } \\
\text { services }\end{array}$ & $\mathfrak{E} 67$ (232) & $\mathfrak{E} 54(213)$ & $\mathfrak{E} 57(218)$ & $58(219)$ \\
\hline Anti-depressants & $\mathfrak{E} 12(20)$ & $\mathfrak{E} 12(21)$ & $\mathfrak{E} 11$ (19) & $12(20)$ \\
\hline Other medications & $\mathfrak{E} 17^{3}(13)$ & $\mathfrak{E} 12^{1,3}(14)$ & $\mathfrak{E} 15^{1}(15)$ & $14(15)$ \\
\hline Total costs & 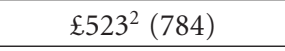 & $£ 460^{1}(787)$ & $\mathfrak{E} 322^{1,2}(386)$ & $457(738)$ \\
\hline
\end{tabular}

${ }^{a}$ See Table 4 for services included in each category.

${ }^{1}$ Significant difference between dysthymia and recurrent depression groups.

${ }^{2}$ Significant difference between dysthymia and chronic major depression groups.

${ }^{3}$ Significant difference between recurrent depression and chronic major depression groups.

of depression and levels of functional impairment, a similar proportion of people in each of the three groups had used each of the services with two exceptions. Table 4 shows that, compared to the other groups, those with dysthymia were less likely to be in contact with any mental health services and a higher proportion those with recurrent depression had seen an alternative (complementary) therapist.

The majority of the sample (74\%) had been prescribed anti-depressant medication in the previous 3 months, including $80 \%$ of those with chronic major depression, $72 \%$ of those with recurrent depression, and 70\% with dysthymia. Anti-depressants were by far the most commonly prescribed medication in this population.

Table 5 shows the costs of support for each diagnostic group over the 3-month period. Hospital costs account for the highest proportion of total costs for the total sample and also within each diagnostic group (around a third), followed by primary care and mental health services. Cost differences between groups generally reflect the service use patterns (Table 4). Average costs for primary care and other health and community services were similar in each group.

Bootstrapped $t$-tests found significantly higher mean costs for the recurrent depression and chronic major depression groups compared to those with dysthymia for mental health services, alternative therapy, and total costs. Those with recurrent depression also had higher costs for alternative therapy and significantly lower costs for "other medications" than those with chronic major depression.

\section{Discussion}

Three groups were identified among this sample of primary care patients based on the DSM-IV diagnostic criteria for chronic major depression, recurrent depression, or dysthymia. The sample as a whole was characterised by very high levels of depressive symptoms and functional impairment, and the majority had been prescribed anti-depressants in the preceding three months. Those with chronic major depression were the most depressed and impaired of the three groups. Compared to the other two groups, they had the highest costs for mental health service use and the costs for their full service package were also highest (final row, Table 5). People with dysthymia were the least depressed and had less severe functional impairment; their total service costs were lowest, as was the proportion in contact with mental health services.

All three groups made considerable use of GPs, with on average slightly more than one GP consultation for depression and more than one consultation for other reasons in the previous three months. If the three months prior to interview are representative of the full year, these suggest higher contact rates than in the population as a whole. National data show women have an average of five GP appointments per year for all reasons and men have four [18].

Levels of depression were much higher among our sample than reported in another primary care study of recurrent depression which used the BDI-II as an outcome measure [7], but this may be due to the eligibility criterion for this study (above 14 on the BDI-II) which was intended to ensure inclusion of those with at least minor depression at the point of recruitment. However, our findings support previous research showing reductions in functioning and well-being for depressed patients that equal or exceed those of patients with other chronic illnesses [19].

The percentage of participants in paid employment was lower than reported in other studies of primary care patients with depression [20], reflecting the greater impairment likely to be associated with chronic or recurrent depression. In line with other findings, the participants with chronic major depression were least likely to be in paid employment. In our sample, men reported significantly higher functional impairment than women, but the severity of their depression was similar. Notably, more than three-quarters of participants had received a prescription for anti-depressants within 
the past three months, but most continued to have very high levels of depression and associated functional impairment, which suggests that anti-depressant therapy is far from optimal in this group. Around a quarter had seen a mental health professional in the past three months, but most of these contacts were with a counsellor.

A limitation of this study is that participants were specifically recruited for a research study and may not therefore be representative of the whole population of people with chronic or recurrent depression in primary care. There were fewer GP practices from inner city areas participating in the study, and our sample therefore underrepresents populations from these areas. This may affect the generalisability of our findings to more ethnically and socially diverse inner city populations. Nonetheless, our large study sample comprises a rigorously selected group of patients and indicates the high levels of morbidity and functional impairment associated with chronic major depression, recurrent major depression, and dysthymia, as well as the differences between these three diagnostic groups.

People with chronic/recurrent major depression and dysthymia form clinically important patient groups for primary care practitioners. Nearly two-thirds of our sample had severe depressive symptoms and high functional impairment, despite the majority receiving anti-depressant treatment. Most were being treated entirely in a primary care setting where regular followup and review may be lacking $[21,22]$. The chronic nature of their problems and high rates of attendance in primary care suggests they are particularly challenging for GPs to work with. Moreover, one in four of those in our study with chronic major or recurrent depression had also seen a mental health professional, at least one in three of the whole sample had attended a hospitalbased service, and one in four had contact with at least one other health or community care service during the three months prior to the start of the main study. Further data collected prospectively for this sample within the overarching trial will allow us to test whether a structured proactive practice nurse-led intervention is an effective form of intervention for this group.

\section{Acknowledgments}

This work was supported by The Big Lottery, grant code RG/1/010166750. The authors would like to acknowledge and thank the Big Lottery as the funders of this research and the voluntary organisation Mind who are our collaborators. We would also like to thank the Medical Research Council General Practice Research Framework (MRC GPRF) nurses, participating practices and patients for their involvement, as well as the nurses, practices and patients from the four non-GPRF practices involved. We have also received valuable support from the Mental Health Research Network (MHRN) and the Primary Care Research Network (PCRN). Ethical approval was granted by the Royal Free Hospital and Medical School Ethics Committee-REC reference number 07/Q0501/15. Trial registration number: ISRCTN36610074.

\section{References}

[1] N. Singleton et al., Psychiatric Morbidity Among Adults Living in Private Households 2000, Office of National Statistics, London, UK, 2001.

[2] C. M. Thomas and S. Morris, "Cost of depression among adults in England in 2000," British Journal of Psychiatry, vol. 183, pp. 514-519, 2003.

[3] E. van Weel-Baumgarten, W. van Den Bosch, H. van Den Hoogen, and F. G. Zitman, "Ten year follow-up of depression after diagnosis in general practice," British Journal of General Practice, vol. 48, no. 435, pp. 1643-1646, 1998.

[4] L. L. Judd, "The clinical course of unipolar major depressive disorders," Archives of General Psychiatry, vol. 54, no. 11, pp. 989-991, 1997.

[5] N. Singleton and G. Lewis, Better or Worse: A Longitudinal Study of the Mental Health of Adults Living in Private Households in Great Britain, 2003.

[6] D. A. Solomon, M. B. Keller, A. C. Leon et al., "Multiple recurrences of major depressive disorder," American Journal of Psychiatry, vol. 157, no. 2, pp. 229-233, 2000.

[7] H. J. Conradi, P. de Jonge, and J. Ormel, "Prediction of the three-year course of recurrent depression in primary care patients: different risk factors for different outcomes," Journal of Affective Disorders, vol. 105, no. 1-3, pp. 267-271, 2008.

[8] K. R. Lloyd, R. Jenkins, and A. Mann, "Long term outcome of patients with neurotic illness in general practice," British Medical Journal, vol. 313, no. 7048, pp. 26-28, 1996.

[9] M. Buszewicz, M. Griffin, E. M. McMahon, J. Beecham, and M. King, "Evaluation of a system of structured, pro-active care for chronic depression in primary care: a randomised controlled trial," BMC Psychiatry, vol. 10, article 61, 2010.

[10] American Psychiatric Association, Diagnostic and Statistical Manual of Mental Disorders, Washington, DC, USA, 4th edition, 1994.

[11] A. T. Beck, R. A. Steer, G. K. Brown et al., Manual for the Beck Depression Inventory-II, San Antonio, Tex, USA, 1996.

[12] J. C. Mundt, I. M. Marks, M. K. Shear, and J. H. Greist, "The work and social adjustment scale: a simple measure of impairment in functioning," British Journal of Psychiatry, vol. 180, pp. 461-464, 2002.

[13] J. Beecham and M. Knapp, "Costing psychiatric interventions," in Measuring Mental Health Needs, G. Thornicroft, Ed., p. 200, Royal College of Psychiatrists, London, UK, 2001.

[14] L. Curtis, Unit Costs of Health and Social Care 2008, Personal Social Services Research Unit, University of Kent, Canterbury, UK, 2008, Edited by L. Curtis.

[15] Department of Health, "NHS reference costs 2007-08," 2009.

[16] J. Beecham, "Collecting and estimating costs," in The Economic Evaluation of Mental Health Care, M. Knapp, Ed., pp. 157-174, Arena, Aldershot, UK, 1995.

[17] B. Efron and R. Tibshirani, An Introduction to the Bootstrap, vol. 57 of Monographs on Statistics and Applied Probability, Chapman \& Hall, New York, NY, USA, 1993.

[18] "ONS General Household Survey," 2006, Office for National Statistics (2008), General Household Survey 2006 Overview Report.

[19] R. D. Hays, K. B. Wells, C. D. Sherbourne, W. Rogers, and K. Spritzer, "Functioning and well-being outcomes of patients with depression compared with chronic general medical illnesses," Archives of General Psychiatry, vol. 52, no. 1, pp. 1119, 1995. 
[20] W. Katon, E. Lin, M. von Korff et al., "The predictors of persistence of depression in primary care," Journal of Affective Disorders, vol. 31, no. 2, pp. 81-90, 1994.

[21] E. H. B. Lin, W. J. Katon, G. E. Simon et al., "Low-intensity treatment of depression in primary care: is it problematic?" General Hospital Psychiatry, vol. 22, no. 2, pp. 78-83, 2000.

[22] K. Rost, P. Nutting, J. L. Smith, C. E. Elliott, and M. Dickinson, "Managing depression as a chronic disease: a randomised trial of ongoing treatment in primary care," British Medical Journal, vol. 325, no. 7370, pp. 934-937, 2002. 


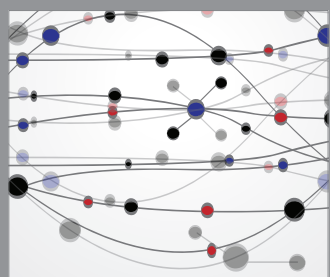

The Scientific World Journal
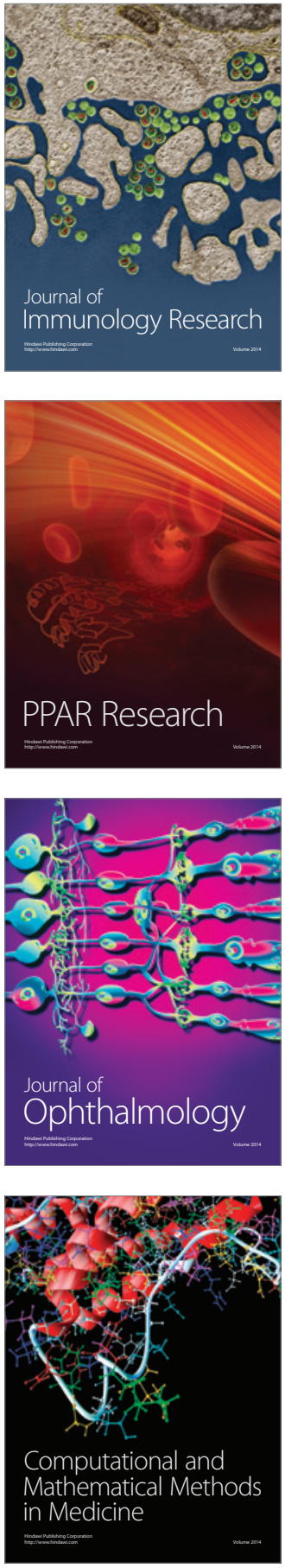

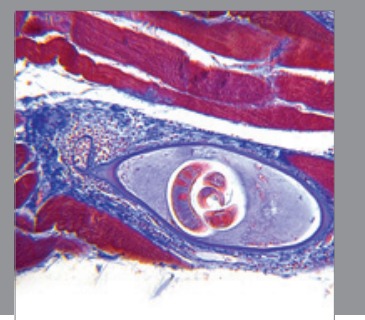

Gastroenterology

Research and Practice
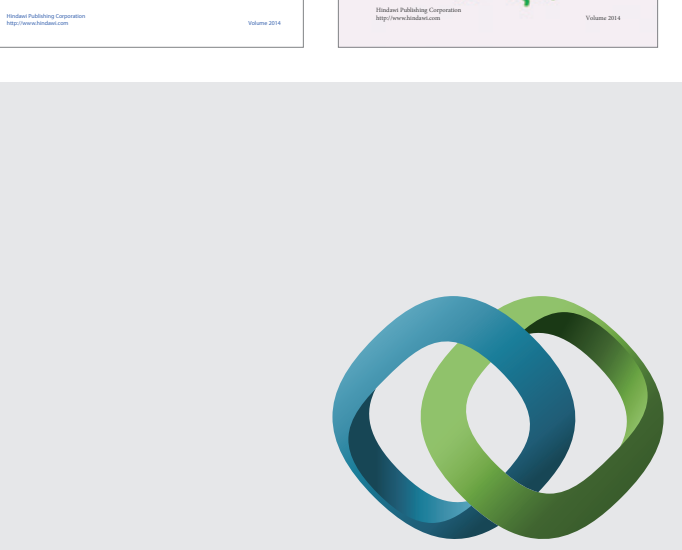

\section{Hindawi}

Submit your manuscripts at

http://www.hindawi.com
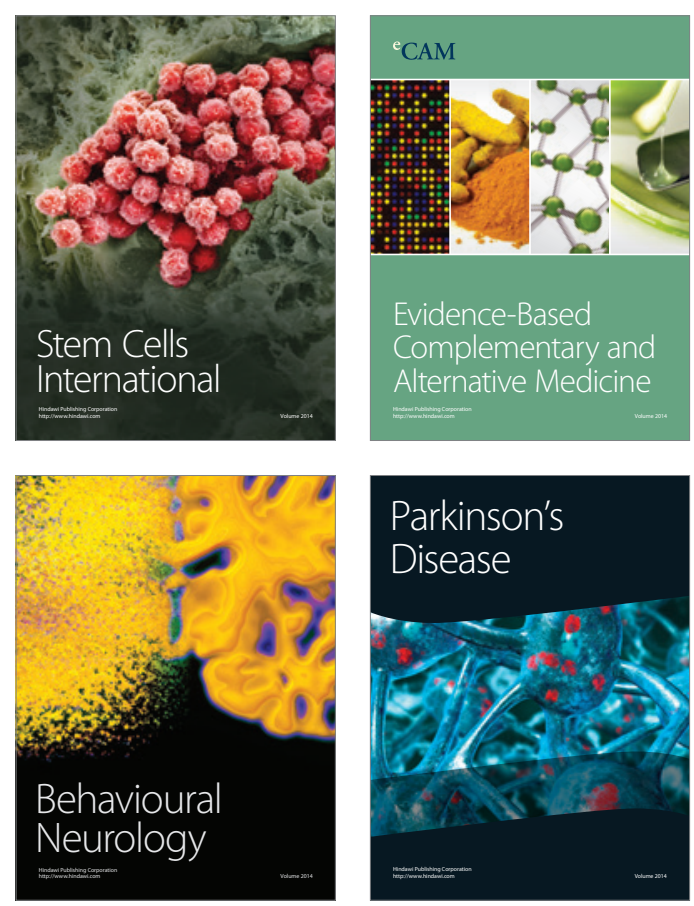

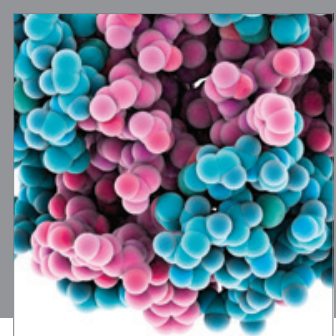

Journal of
Diabetes Research

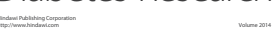

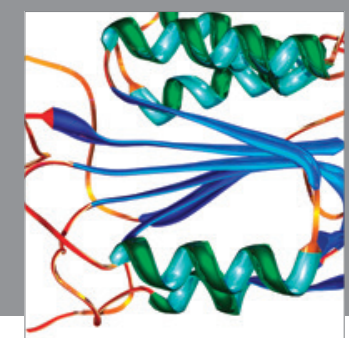

Disease Markers
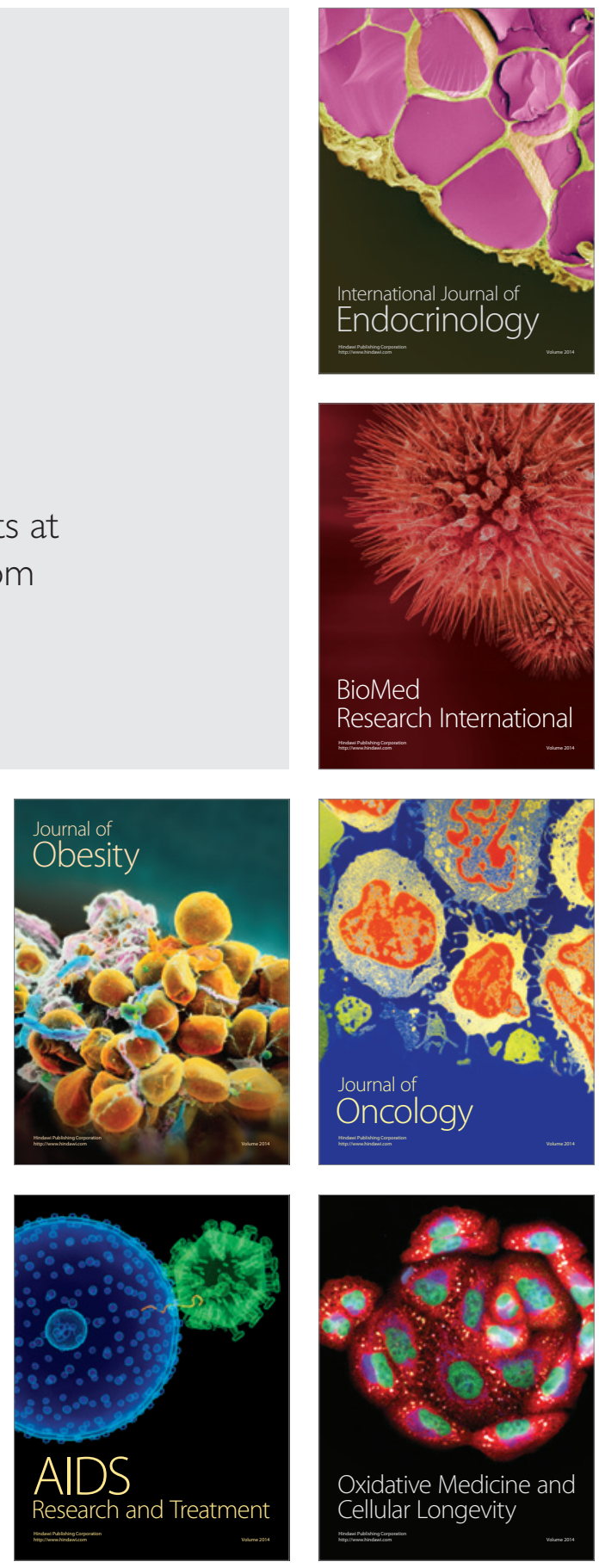